\title{
Classification and Quantification of Cultural Basements and Elements Used in Multicultural Families
}

\author{
Author: Kamil Rafikov \\ ORCID: 0000-0002-7828-2488 \\ Email: mailbox@kamil-rafik.com \\ This document is distributed under CC BY 4.0 license. \\ DOI: $10.5281 /$ zenodo.4027218 \\ Updated at October $11^{\text {th }}, 2021$. \\ Edition: 15.
}

\section{Table of Contents}

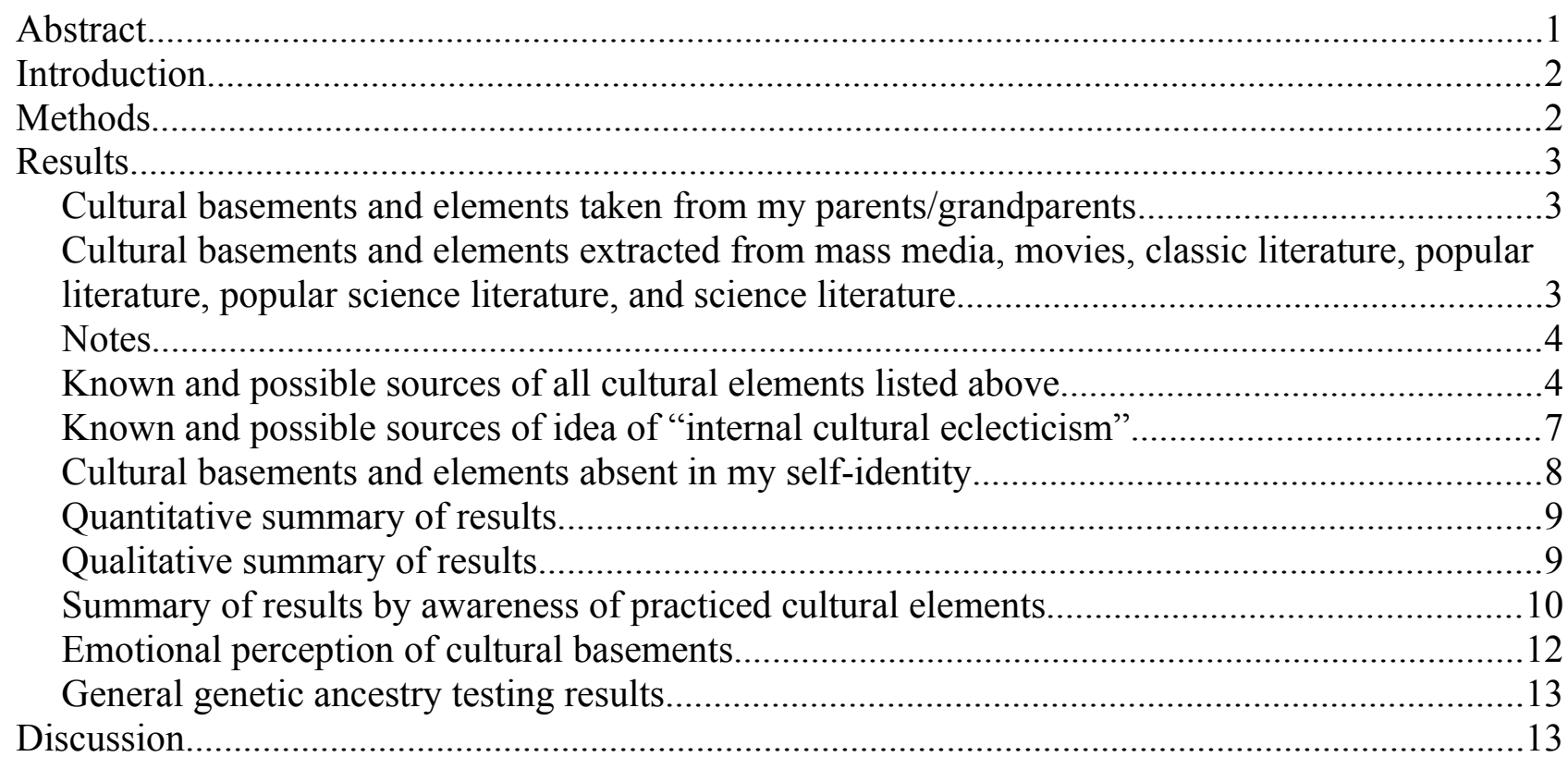

\begin{abstract}
Autoethnographic research for structuring personal cultural background formed in multicultural family in the period of social and economic collapse. In the process of research, the following has been discovered: a) respondent may practice regularly more than 30 cultural elements obtained from 8 cultural basements unrelated to each other; b) practiced cultural basements and elements may follow some strict numeric and categorical patterns that may have different social implications; c) cultural basements and elements considered by respondent as main may be practiced unconsciously until getting into conflicts with relatives and society; d) even minor source of information or minor detail of daily lifestyle which is insignificant at the first sight may influence adult life heavily; e) "exotic" cultures practiced by respondent may relate to his factual undocumented genetic ancestry even if amount of this ancestry does not exceed several percents.
\end{abstract}




\section{Introduction}

The purpose of this autoethnographic research consists of describing and structuring personal cultural background that directed general lifestyle, career, psychological development, personal life, and self-education in the period since getting 11 years old until getting $40+$ years old. In the process of structuring, several unexpected regularities and facts have been found. All discovered regularities and facts may be either my personal particularity or something universal not depending on my cultures, ethnicities, or cognitive processes; more detailed research of this topic with large number of respondents is desired.

The document contains the draft version of research; the research was performed since the end of $2019^{\text {th }}$ year till the current time; initially it was done in the process of writing guide on building family and parenting models that was published at https://doi.org/10.5281/zenodo.3576245, later it was continued independently. The very first version written in the format of research proposal has been included in the collection of ideas for social researches published at https://doi.org/10.5281/zenodo.3364008.

\section{Methods}

Initial results in the format of list of cultural basements and elements have been summarized by recalling multiple details of life in memory within one day at the end of $2019^{\text {th }}$ year. Then, several elements have been added within several weeks. After that more details were uncovered in the process of regrouping collected data and clarifying every item.

The term cultural basement describes general set of cultural constructs and practices used within particular geographical region, ethnic group, religious community, professional community, or recreational community (like cultures of professional musicians or amateur musicians, for example). The term cultural element describes one of cultural constructs and practices used within particular cultural basement. All listed cultural basements and elements were thought about and/or verbalized somehow in the period since getting 11 years old until getting 18 years old; however, the first full summary has been created just when I was $40+$ years old already. In other words, usage of these cultural basement and elements was semi-conscious within almost 25-30 years. By now, almost all of them may be considered either as abandoned experience from the past or as natural eternal part of my personality.

In spite of active usage of religious cultural basements, I'm neither religious nor believer; these basements were used without practicing religious ceremonies and without accepting existence of $\operatorname{god}(\mathrm{s})$.

It is obvious that some elements may be freely regrouped between basements because they are rather universal; in my case, they were grouped as provided further in according to source of information about element (particular relative or book purchased by particular relative, for example), or in according to cultural/psychological communication context where the element was taken from. 
Summary of results is given outside of genealogical, ethnic, demographic, historical, psychological, medical, and economical contexts to avoid digging too deeply (just main social environment details are given to allow inexperienced reader to understand the text); it is a topic for much more detailed research involving group of scientists with multidisciplinary background and large budget.

\section{Results}

\section{Cultural basements and elements taken from my parents/grandparents}

- “Ashkenazi Jewish" - strict monogamy, concentration at education and self-learning, being either business-oriented or science-oriented or arts-oriented in professional life, females playing dominant role in family relationships, practicing basics of kashrut;

- "general Central Asian" - village-style thinking, high fertility, obedience to state, acceptance of superiority of Islamic culture and generally Semitic cultures;

- "Russian/Soviet" - Soviet internationalism (Soviet ideology of multiculturalism limited to USSR and friendly countries), separating ordinary life stream from official state ideology stream, using Russian language as primary one in family relationships, being Europe-oriented;

- "general Islamic" - obedience to supernatural forces in daily life, considering knowledge of Arabic language as desired, so-called "Islamic/Semitic internationalism" (the term is created by me to describe transition of Soviet internationalism ideology to the whole Islamic/Semitic world, but, as I remember, similar concept really exists in Islam), giving Arabic first names to kids.

\section{Cultural basements and elements extracted from mass media, movies, classic literature, popular literature, popular science literature, and science literature}

Some elements listed further may look strange for person grown up in Russia, but you should understand that I grew up in 1980's and 1990's in the situation of economical/political collapse and expansion of Western cultures into Russian/Soviet mass media. At the same time, you should note that active reading and watching of TV programs and movies were encouraged by parents and grandparents; that's why all absorbed cultural material had psychological foundation in interpersonal family relationships (for example, father and mother purchased literature in different genres/styles with training different parts of my mind appropriately).

- "Mediterranean" - deep relatedness between family members, being arts-oriented in professional life, public demonstration of affection and sexuality, considering Mediterranean region residence or US residence as prerequisites for family building and successful life;

- "Protestant" - labour-based life philosophy (up to using labour as one of sexual sublimation methods), individualism, nuclear family, considering US residence as prerequisite for family building and successful life; 
- “modern US” (“modern” for 1980's and 1990’s) - multiculturalism, high mobility, considering residence in one of international megalopolises as prerequisite for family building and successful life, obedience to laws, regular sportive training;

- "exotic anthropological" - using elements of traditional visual cultures and lifestyles as elements of sexual play between spouses (considering females in exotic traditional clothes as very sexually attractive, and generally folk-music culture as sexy one), orientation towards living in nature and "being green" in daily lifestyle, using science as basement for family relationships and other parts of life, giving "exotic" first names to kids (I had not and I have not kids, but the idea about giving "exotic" first names was reviewed by me firstly in teenage years).

\section{Notes}

- The following items have been recalled in memory in several weeks after writing down the most part of background: practicing basics of kashrut, giving Arabic names to kids, regular sportive training, and giving "exotic" names to kids. No more items have been recalled after that.

- Cultural basements are listed in the order of significance from the most significant to less significant. Order of cultural basements and elements extracted from mass media, movies, classic literature, popular literature, popular science literature, and science literature does not relate to the order of basements and elements extracted from personal communication with parents and grandparents. In other words, it is a separate set of the same significance as the previous one.

- Hierarchy and structuring given above reflect situation by the time when I was about 18 years old. Later, under pressure of the society and in the process of getting older, sub-conscious regrouping and mixing of all elements into the single whole has been performed. Connection of elements to cultural basements has been lost. So, currently (when I'm 40+ years old), the provided structures do not reflect my vision of the world at all.

- To understand historical context where described cultural self-identity was formed it is required to mention that I was born in $1978^{\text {th }}$ year (at the peak of economical development of USSR), and USSR has collapsed when I was about 13 years old. Widespread Internet access was not available yet by the time when I was 18 years old.

\section{Known and possible sources of all cultural elements listed above}

As you can see further, some elements are in fact take roots from 1-3 minor sources which are insignificant at the first sight, although their subsequent influence on adult life may be huge.

- The elements "strict monogamy" and "females playing dominant role in family relationships" come from daily communication between my parents and between my grandparents. 
- Intellectual stimulation has been performed by all family members, but only Jewish grandmother could create comfortable psychological environment for self-learning; that's why the element "concentration at education and self-learning" is listed in the context of Ashkenazi Jewish culture.

- Professional orientation towards business, science, and arts was standard in educated Jewish families in USSR of the second half of $20^{\text {th }}$ century.

- Practicing basics of kashrut included only absence of pork in daily meal. (Meal always was prepared by females in family of my parents/grandparents, that's why it is not mentioned as "practicing basics of halal" which is almost the same.) When I lived with parents and grandparents, pork never was consumed; at least once, theoretical explanation of kashrut was given to me in my early childhood by grandmother. Until now, just by habit, I still don't consume pork, except rare situations when other sorts of meat are completely absent, and I need to eat much.

- My grandparents grew up in villages of Tatarstan and Ukraine (Odessa area). (I mention Tatarstan but not Russia, because my parents and grandparents never considered themselves as Russians.) My father and mother grew up in towns of Uzbekistan and Kyrgyzstan, but we never had local relatives there; I visited these two countries in adult age only, and in daily communication with locals, I understood that I'm somewhat close to them psychologically. (For those who don't know this region, it is worth to mention that both nations are rather different and have some tensions in communication, the information is obtained from informal talks with young Kyrgyz ladies.) So, it turned out that almost whole Central Asian cultural basement came to me from Southern parts of Central Asia, although I have no ethnic ancestry there at all (maybe, except genetic micro-admixtures of several percents). However, the idea of "superiority of Islamic culture and generally Semitic cultures" has its main roots in my interests in world history; it is obvious for every historian where the world civilization began; in other words, superiority mentioned in this element has mainly relative historical meaning, but not chauvinistic one (although, in its Central Asian origin the idea could be really based on chauvinism).

- The idea of "Soviet internationalism" came to my mind from three sources: daily life of my direct relatives; one child book that I have read when I was around 7 years old, there was a picture of happy people of all Soviet ethnic groups in ethnic clothes, at those times I did not separate literature from family life, all came to my mind together; and finally, from studies in ordinary school in Kazan which were also just addition to family life when I was about 7-10 years old. Also, when I was about 10 years old, there was one case of communication with Jewish grandmother about our countryside house (it is translation of the Russian term $\partial а ч а)$ neighbors of Estonian origin: she told that they are nationalists; it was told quietly and in such tone that I understood that being nationalist is something very bad, so bad that it should not be even discussed.

- Usage of Russian language for daily communication between Tatars was considered as norm in Tatarstan of 1980's and 1990's. 
- The idea of "separating ordinary life stream from official state ideology stream" came to my mind upon observing communication between my parents and grandparents in my childhood, although I was too little to understand real sense of their emotions.

- The idea of being Europe-oriented came to my mind primarily from the fact of having large home library with hundreds of books of European and American classic and adventure authors purchased by my mother when she was young. In other words, from the fact of having these books at home, not from reading them (although I have started to read them at getting 7 years old). Also, TV discussions at the peak of Perestroika about future paths of Soviet society development made some influence. When I was around 12 years old, at one of history lessons, the teacher (who probably made her own Ph.D. in local university) asked kids to respond some questionnaire about cultural identity, I thought a little, and wrote there "European". However, I did not concentrate at this moment much; the questions of cultural self-identity did not bother me at those times at all.

- Probably, obedience to supernatural forces was cultivated primarily by my father repeating "Allah berse" regularly (which means the same as "InshAllah"). At least once, in my childhood, one of my grandfathers forced me to perform some Islamic religious ritual before dinner. I didn't practice anything of this by myself, but I'm superstitious a little; this superstitiousness is supported by some risky travels I make, and generally, by my lifestyle. In fact, in regular life, I don't believe in existence of supernatural forces, but when I'm extremely stressed or when I come to the edge of my possibilities (this period of "walking on the edge" may take months), I feel "primordial fear of obscurity" which causes me to believe in "something supernatural".

- Learning Arabic language was considered by me as one more step towards globalization. Although my father used Arabic grammar books for regular training of mind after getting 40 years old, and for supporting his own public image as "person respecting Islamic culture" in his business networks.

- The idea of "Islamic/Semitic internationalism" has its roots in having some books at home too. My father had a large collection of linguistic literature about languages of Arabic countries, Turkey, Iran, Morocco, Ethiopia, Indostan, and read parts of this literature regularly by himself. I did not read these books actively, just browsed from time to time.

- Arabic names were given to kids by my father as attempt to make us "oriented towards historical Middle East" (he never visited real modern Middle East). I kept my name because I liked it; moreover, I accept idea of giving Arabic names to my own kids in the future, because there is high chance that my future wife may be from some region where such names are widespread too.

- "Mediterranean" cultural basement takes first place in the second list also because of my interests in world history and because of my interests in classic visual arts (from antiquity up to $19^{\text {th }}$ century). So, its relative position in the list has also primarily historical and artistic meaning, but not chauvinistic one. Idea of "deep relatedness between family members" was 
taken from Mario Puzo's novel "The Godfather". Idea of "public demonstration of affection and sexuality" has its roots in Elton John's music video "A Word in Spanish" (https://youtu.be/T2KZDPuQwrE?list=RDT2KZDPuQwrE). In movies and TV reports that I have seen in 1980's and 1990's, large Southern European families (including those living in US) were displayed as something standard; that's why considering residence in Mediterranean region or US as prerequisite for family life was completely logical.

- "Protestant" cultural basement was primarily taken from Daniel Defoe's "Robinson Crusoe" novel (the main "super-male" character of the novel identifies himself as "Protestant" in a talk with ship captain by the end of the novel), from Hollywood movies where wedding happens in Anglican church, and from TV reports about rich ordinary life in US (such reports were very popular in 1980's and 1990's).

- Idea about living in international megalopolises is based on American and European movies where all attractive characters live in cities like New York. Idea about regular sportive training is based on photos of US bodybuilders in popular sportive magazines. Multiculturalism, obedience to laws, and high mobility were described in TV reports and social dramas as something natural and obligatory for living in US.

- The idea of "using elements of traditional visual cultures and lifestyles as elements of sexual play between spouses" comes from books in its conscious form. But I guess, its real roots may lay in multicolored home robes used by my mother and grandmothers when I was little kid. Such multicolored robes are widespread even in the modern Kyrgyzstan and Uzbekistan; this style in home clothes could be brought by mother and grandmothers from the period of residing in South of Central Asia in 1940's - 1960's. (In Tatarstan, it was impossible to see women in such clothes on the streets even in 1980's.) However, all this is just a guess; you should not rely on provided information.

- Ecological thinking comes from popular science authors and TV science movies.

- The idea of "using science as basement for family relationships and other parts of life" came to my head in the period when family of my parents started to break down and I was immersed into reading popular science magazines.

- Affection towards "exotic" names was based on reading adventure novels where all characters having "exotic" names lived much more interesting life than I had.

\section{Known and possible sources of idea of "internal cultural eclecticism"}

The whole approach to building self-identity in eclectic style is based on four sources probably, where the first source was the main one, as I guess.

- Around getting 5-7 years old I was advised by my grandfather to watch an old Indian movie shown at TV where Raj Kapoor performs the song "Mera Joota Hai Japani", https://www.youtube.com/watch? $\mathrm{v}=5 \mathrm{wjGc1zGWBc}$, the refrain of the song is translated approximately as "My shoes are Japanese, the pants are British, red Russian hat is on my head, but my heart is Indian". It was my first encounter of the idea of so-called internal 
cultural eclecticism (the term is invented by myself). All other encounters happened much later when I became teenager.

- In the process of exploring US culture through TV reports, I have met the concept of melting pot.

- In regular trips with parents from Kazan city to countryside house ( $\partial а ч a)$, I had a chance to see multiple times the Temple of All Religions located close to railways. You may read about it and see photos by the following link:

https://en.wikipedia.org/wiki/Temple of_All_Religions

- And finally in the process of self-studies of world history and world arts history, I have met in one encyclopedia the term eclecticism in application to artworks, and I liked this approach a lot although I did not apply it to my self-identity at those times.

\section{Cultural basements and elements absent in my self-identity}

It is supposed that in the process of performing similar research with other respondents it is reasonable to check not only what is/was present in the mind of respondent, but also what is/was absent although could be present. To understand what I mean, just look at the following clarifications.

- The concept of race is almost absent in social life of Russia, and particularly in social life of Tatarstan (at least, in the circle of communication I had until 22 years old); I met it first time in adult age only when I started working with other Jews in IT businesses and when I started searching job in US (for remote employment and for migration). The concept of religion was considered as "something archaic" in the circle of communication I had until 22 years old; propaganda of atheism was still active in elementary school in the last years of USSR. The concept of Soviet nation was actively criticized on TV in 1980's and 1990's; and this nation really disappeared soon. The concept of ethnicity was heavily blurred by Soviet internationalism ideology (at least, in Tatarstan, in my circle of communication). The concept of family could not be used as solid ground of life because at 1980's and 1990's the family of my parents/grandparents started to break down. All this may explain easily why my vision of life gave such large attention to the concept of culture.

- Such regions as Latin America, Africa, Indostan, China, South-East Asia, Oceania did not influence me directly, because their economic situation at 1980's and 1990's did not allow them to distribute cultural propaganda actively. However, they were used in some or another way in practiced cultural elements too; at least, in locations of adventure novels or in life stories of famous people (like Paul Gauguin etc). Indian movies were watched for some period of time, but due to strange coincidence they were made in Islamic regions of India, included Islamic propaganda, and that's why they were absorbed in the context of global Islamic culture. Medieval East Asian literature was read actively, but it was done in the context of interests in arts and exotic anthropology. 
- Access to recreational cultures was very limited due to economical problems of 1990's, only reading books/magazines and watching TV/movies was possible in large amount. Practice in drawing was limited with dull local landscapes and lack of interest in local females. Playing music and dances were not very interesting for me. Hiking in mountains or at sea was impossible due to absence of mountains and sea in the region where I lived.

- Constructing professional cultural basements was impossible partially due to criminalized economics and partially due to ideological conflicts with parents who considered me as kid until adult age and did not assist much in finding really suitable professional niche.

\section{Quantitative summary of results}

So, we have 2 sets of cultural basements being used since getting 11 years old until getting $40+$ years old. There are 4 basements in each of sets of basements. Each basement consists of 4-5 elements. The total of elements in each set is 17. The basement with 5 elements may have lower significance than basement with 4 elements.

2 elements in each set may be classified as "compound" or "complex" elements consisting of several items: "concentration at education and self-learning", "being either business-oriented or science-oriented or arts-oriented in professional life", "considering Mediterranean region residence or US residence as prerequisites for family building and successful life", "orientation towards living in nature and "being green" in daily lifestyle".

\section{Qualitative summary of results}

All elements listed above may be roughly regrouped in 17 groups reflecting different aspects of social life (although, approach to regrouping and total number of groups may be highly debated):

- "family structure" - strict monogamy, females playing dominant role in family relationships, high fertility, deep relatedness between family members, nuclear family;

- "role and methods of education" - concentration at education and self-learning;

- "career options" - being either business-oriented or science-oriented or arts-oriented in professional life;

- "religious practices" - practicing basics of kashrut;

- "general life philosophy" - village-style thinking, individualism;

- "obedience to external forces" - obedience to state, separating ordinary life stream from official state ideology stream, obedience to supernatural forces in daily life, obedience to laws;

- "superiority of particular ethnocultural groups" - acceptance of superiority of Islamic culture and generally Semitic cultures, being Europe-oriented;

- "geography of internationalism and multiculturalism" - Soviet internationalism, so-called "Islamic/Semitic internationalism", US multiculturalism; 
- "languages" - using Russian language as primary one in family relationships, considering knowledge of Arabic language as desired;

- "names given to kids" - giving Arabic or "exotic" first names to kids;

- "role of sex" - public demonstration of affection and sexuality, using elements of traditional visual cultures and lifestyles as elements of sexual play between spouses;

- "migration routes" - considering Mediterranean region residence or US residence or residence in one of international megalopolises as prerequisite for family building and successful life;

- "role of labour" - labour-based life philosophy;

- "mobility" - high mobility;

- "role of sports" - regular sportive training;

- "attitude to nature" - orientation towards living in nature and "being green" in daily lifestyle;

- "role of science" - using science as basement for family relationships and other parts of life.

\section{Summary of results by awareness of practiced cultural elements}

Some elements that have clear definitions could be absorbed exactly in the format of these definitions from the very beginning; others could be thought about by myself in some unclear formats for a long period of time before finding definitions in external sources (finding could occur as before getting 18 years old as after that); and for some the process of absorbing senses and absorbing definitions (upon encountering them multiple times) could go simultaneously for a long period of time. Now, it is almost impossible to recall such details in memory. The only remembered details concerning awareness of practiced cultural elements are given further.

Elements consciously practiced since childhood with clear understanding their relation to the specified basement; the list includes 16 elements, and as you can see, mainly it includes cultural influence coming from external sources outside of family relationships:

- $\quad$ separating ordinary life stream from official state ideology stream;

- using Russian language as primary one in family relationships;

- being Europe-oriented;

- considering knowledge of Arabic language as desired;

- deep relatedness between family members;

- being arts-oriented in professional life;

- considering Mediterranean region residence or US residence as prerequisites for family building and successful life; 
- labour-based life philosophy;

- individualism;

- nuclear family;

- considering US residence as prerequisite for family building and successful life;

- multiculturalism;

- $\quad$ high mobility;

- considering residence in one of international megalopolises as prerequisite for family building and successful life;

- obedience to laws;

- regular sportive training;

Elements consciously practiced since childhood but verbalized and grouped by basement in adult age only after analyzing other people's opinions about myself, but before writing this document; the list includes 16 elements too, and as you can see, mainly it includes either elements cultivated inside family or elements that I always considered as insignificant:

- $\quad$ strict monogamy;

- concentration at education and self-learning;

- being either business-oriented or science-oriented or arts-oriented in professional life;

- females playing dominant role in family relationships;

- village-style thinking;

- $\quad$ high fertility;

- obedience to state;

- acceptance of superiority of Islamic culture and generally Semitic cultures;

- Soviet internationalism;

- so-called "Islamic/Semitic internationalism";

- giving Arabic first names to kids;

- public demonstration of affection and sexuality;

- using elements of traditional visual cultures and lifestyles as elements of sexual play between spouses;

- orientation towards living in nature and "being green" in daily lifestyle;

- using science as basement for family relationships and other parts of life;

- giving "exotic" first names to kids. 
Elements practiced since childhood but verbalized in the process of writing this document only; the list includes only 2 elements, one is performed just by habit, another one is semi-conscious and has been practiced in extreme circumstances only:

- $\quad$ practicing basics of kashrut;

- obedience to supernatural forces in daily life.

\section{Emotional perception of cultural basements}

To provide the full picture, I can describe my emotional perception of used cultural basements by the time when I was about 18 years old.

- “Ashkenazi Jewish" - no conscious emotional perception was present. Due to historical reasons Jewish admixture never was verbalized actively in the family of my parents and grandparents, but at the same time Jewish grandmother was head of the family, and daily life elements obtained from this culture were semi-consciously considered by me as primary in my life. It should be noted that since youth until getting retired my Jewish grandmother lived under false Russian name similar to her original Jewish one and under false Russified form of patronymic; original name and patronymic have been restored just after getting retired. I started to identify myself as Jewish only later, after getting 18 years old, when I entered multiple conflicts with my relatives and with society due to impossibility to continue practicing in adult life all cultural elements of that basement: so, I needed to analyze what I do and why, and after analyzing, I came to the conclusion that all things which were main in my life at those times originated from common Ashkenazi Jewish culture. It should be noted that adjective Ashkenazi was found by me in Internet just by getting 27 years old (although I started to identify myself as Jewish earlier)! It explains how far I was from being interested in my ancestry before that and how far I was from local Jewish community. Before that, psychological and life approach differences between myself and other people were explained by me to myself with "my rich individuality", "being Europe-oriented", "being US-oriented", "being smarter than others", "being crazy"; only after starting active social life and comparing myself to other people I came to understanding what was the real reason of the differences.

- “General Central Asian" - "utilitarian, outdated".

- "Russian/Soviet" - "utilitarian, outdated".

- “General Islamic" - “archaic, insignificant”.

- “Mediterranean" - “desired, beautiful".

- "Protestant" - "reasonable, good".

- "Modern US" - "desired, lively".

• "Exotic Anthropological" - “insignificant, peculiar". 
So, you may see that only two of used basements were considered as "desired", one ("Protestant") is going as "addition" to these two, one was practiced unconsciously, and all other were considered as outdated, archaic, and insignificant. It explains completely large number of used cultural basements.

\section{General genetic ancestry testing results}

After getting results of genetic ancestry testing made in adult age, it was found that I have ancestry in all geographical regions where my cultural basements came from at least in amount of several percents per each region. Possibly, even some really "exotic" ancestry from very far regions (not used for constructing cultural identity) is present. The map of results changed many times during several years after submission of DNA sample to testing service; so, attaching it here has not much sense.

\section{Discussion}

The most important facts highlighted in this research are the following: a) respondent may practice regularly more than 30 cultural elements obtained from 8 cultural basements unrelated to each other; b) practiced cultural basements and elements may follow some strict numeric and categorical patterns; c) cultural basements and elements considered by respondent as main may be practiced unconsciously until getting into conflicts (sometimes, only severe conflicts) with relatives and society; d) even minor source of information or minor detail of daily lifestyle which is insignificant at the first sight may influence adult life heavily; e) "exotic" cultures practiced by respondent may relate to his factual undocumented genetic ancestry even if amount of this ancestry does not exceed several percents.

In addition to all listed above, this research demonstrates that structuring of cultural background obtained in childhood and teenage years is possible even for amateur in social sciences and psychology (I have not any degree in these fields); although, for young people assistance of professional interviewer may be needed (because for some of them it may be difficult to understand how they look from the point of view of other people due to lack of life experience).

The only theoretical explanation of the pattern with number 4 that I can propose now is that since birth until getting 7-8 years old I lived with 4 adults (father, mother, grandfather, grandmother). Then, after relocation of grandparents, my 2 younger siblings grew up enough to talk and number of people I communicated at home regularly became 4 again. At the same time, I never had close friends due to cultural differences between me and local population, and the most part of emotional communication was performed with relatives. That's why it could alter my psychology somehow.

The only theoretical explanation of the pattern with number 17 that I can propose now is that it correlates somehow with the moment when I felt myself adult for the first time in my life. (So, for other respondents this number should vary in the range from 13 up to 25 , probably).

If the numbers given above have not any physiological explanation, then such sub-conscious "obsession with numbers and patterns" may be easily explained by the fact that until getting 16 
years old I studied in school with incline towards teaching mathematics and natural science (as usually, in high schools of Russia of that historical period), and starting from 17 years old I studied in technical university where during the first 2 years the most part of taught subjects were higher mathematics and natural sciences too.

Also, it may be possible to dig deeper to understand what meaning different numbers have in different cultures and why they have such meaning. If you don't speak Russian language, you should note that Russian word family (семья) may be translated directly to English as "seven I" (“семь я"). And I clearly remember that this breakdown of the word was played in one book that I have read in early childhood. Maybe, it could influence me somehow, who knows?

And the final possible explanation is that 8 cultures structured by pattern may be just "plumage" for attracting females which I have built sub-consciously in absence of opportunities to build something more reasonable.

Primary directions of research of this topic are given further:

- perform quantitative and qualitative research documented above with large number of respondents, cross-culture studies and cross-nation studies are recommended; monocultural families need to be included in the research too;

- determine underlying principles of extracting particular basements and elements from information streams falling on child/teenager, including influence of genetic and social background;

- determine implications of collected results as on single respondent level as on society level.

For some researches of particular societies/countries it may be also interesting to understand real numbers of so-called "hidden Protestants", "hidden Muslims", and hidden followers of other religious philosophies not declaring officially adherence to them and not performing any religious ceremonies. I guess, collected data may differ significantly from currently published official numbers.

When you will analyze information obtained from other respondents, you should understand that "devil may be in details". For example, "internationalism" may include orientation towards marriage with females from countries covered by "internationalism" ideology, but not only friendly international relationships, and such behavior may cause extremely negative reaction.

Possible social consequence of researching this topic with large group of respondents may consist of recognizing people belonging to more than 3-5 cultures as a separate social group that needs political actions to protect their rights, because, as I think, such personal particularity as having "too many" cultures may make life more difficult for the most part of people, although more interesting from another point of view. But I guess, any involvement of politics into this topic will bring more harm than benefits. Another social consequence may consist of deeper attention of school psychologists to this group of people with a purpose of "equalizing" them. However, it is supposed that such "plumage" of 8 cultures structured by pattern like mine (if it was really "plumage") may be considered as norm for educated males in the modern globalized urbanized society. 